\title{
Macro and Structural Effects of Carbon Tax in China Based on the ECGE Model
}

\author{
Qunli Wu', Chunxiang Li ${ }^{2 *}$, Hongjie Zhang ${ }^{2}$, Jinyu Tian² \\ ${ }^{1}$ Key Laboratory of Low-carbon Development and Electric Power with Renewable Energy Sources, \\ Department of Economics and Management, North China Electric Power University, Baoding, China \\ ${ }^{2}$ Department of Economics and Management, North China Electric Power University, Baoding, China
}

Received: 20 March 2018

Accepted: 6 May 2018

\begin{abstract}
Rapid economic development has brought great pressure to China. Carbon tax could be an ideal economic tool to cope with the environmental pressure. The implementation of carbon tax will exert an influence on the national and sectoral economies as well as reduction. However, few researchers have focused on the carbon tax effect at the sectoral level. Based on SAM 2012, this study develops an ECGE model consisting of the environment module. Then the macro and structural effects of carbon tax are simulated at tax rates of 10-100 yuan/t $\mathrm{CO}_{2}$ in China. Simulation results show that compared with the baseline: 1) Carbon tax has a mild strike on the GDP of China and is effective at reducing emissions. Furthermore, we found that a carbon tax rate of 70 yuan/t $\mathrm{CO}_{2}$ may be an appropriate rate to achieve the Chinese reduction target of carbon intensity in the year 2020. 2) Carbon tax induces an output shrinkage in energy or high-energy-consuming industries by $0.95-7.65 \%$, while there is a slight increase in low-energy-consuming industries. The mining and washing of coal industry (coal) experiences the largest decrease in $\mathrm{CO}_{2}$ emissions and the light industry (lindus) experiences the sharpest decline in carbon intensity.
\end{abstract}

Keywords: carbon tax, ECGE model, macro effect, structural effect, China

\section{Introduction}

In recent decades, with the rapid development of the economy and the increasing consumption of energy, global climate change has become one of the most common issues that all countries need to face. As a responsible country, China has been very active in coping with the climate change issue. In 2009 the Chinese government committed to reducing its carbon intensity by $40-45 \%$ in 2020 compared

*e-mail: 1974714280@qq.com with 2005 levels. In 2014 China officially issued its "National climate change plan (2014 2020)," clearly putting forward in 2020 non-fossil energy accounts for the proportion of primary energy consumption to around $15 \%$ and a series of other energy-saving emission reduction targets [1]. Furthermore, to develop a low-carbon economy, China has proposed a series of energy policies such as resource tax policy and a carbon emission trading system [2]. Compared with other energy policies, a carbon tax is considered to be an effective one [3-4]. Bristow [5] defined carbon tax as a climate for all energy purchases, including natural gas, electricity, gasoline, diesel oil, and so on. At present, 
the countries imposing carbon tax include Finland, Sweden, Ireland, Denmark, Norway, Switzerland, Canada, Japan, Germany, Britain, and so on. Although the tax rates and collection manners imposed across borders are different from each other, they all play a significant role in reducing emissions and alleviating environmental pressure [6]. At present, China is facing serious challenges on responding to climate change and emissions reduction [7-8], so it is particularly critical to promote such a tax in China. Therefore, considering the advantages of the policy itself and the possibility of being implemented in the future of China, this study explores the effect of carbon tax on China so that useful policies can be released to guide its future carbon tax implementation.

Recently, most empirical research has verified the reduction effect of carbon tax. Floros and Vlachou [9] put forward that carbon dioxide emissions in Greece would be reduced by $17.6 \%$ in 1998 if a carbon tax of $\$ 50 / \mathrm{t} \mathrm{CO}_{2}$ was imposed. Wissema and Dellink [10] maintained that a carbon tax of 10-15 euro/t $\mathrm{CO}_{2}$ will lead to Ireland's $\mathrm{CO}_{2}$ emissions reduction by $25.8 \%$ compared with that in 1998. Similar conclusions were also made in the study of Bruvoll and Larsen [11], who argued that during the period of 1990-1999 the average GDP in OECD countries increased by $23 \%$, while greenhouse gas emissions increased by only $4 \%$, and carbon tax played an important role in some countries. Galinato [12] conducted a dynamic CGE model for evaluating the impact of carbon tax on the economy and environment, concluding that carbon tax can be an effective policy instrument to control greenhouse gas emissions. Barker [13] assessed the impact of carbon tax on the UK environment, adopting the energy-economyenvironment model and arguing that the carbon tax will be sufficient to stabilize carbon emissions below the standard level of 12\% during 1990-2005. Meng et al. [14] established a computable general equilibrium model to investigate the effects of a carbon tax of $\$ 23 /$ ton carbon dioxide on the economy and environment. The results indicated that it would significantly reduce emissions. Lou [15] argued that with the increase of carbon tax rate, the marginal change rate of carbon emission intensity per unit carbon tax shows a decreasing trend. Zhou et al. [16] introduced energy efficiency into the CGE model. The results illustrated that the emission reduction rates at the carbon tax of 30 yuan $/ \mathrm{t} \mathrm{CO}_{2}, 60$ yuan/t $\mathrm{CO}_{2}$, and 90 yuan/t $\mathrm{CO}_{2}$ are $5.56 \%, 10.45 \%$, and $14.74 \%$, respectively.

Another important topic pertaining to carbon tax is the macroeconomic effect of carbon tax. Fang et al. [17] examined the impacts of carbon tax on economic growth with carbon tax constraints and found that it is both important and necessary to note the inhibitory effect of these changes on economic growth. Cristian Mardones et al. [18] simulated the economic effects by setting different $\mathrm{CO}_{2}$ tax rates in three Latin American countries (Brazil, Mexico, and Chile), and they argued that the effects of a $\mathrm{CO}_{2}$ tax on sectoral prices in each country are very different for the same tax rate, but these effects are similar in each country when comparing both regulatory scenarios. Anton [19] evaluated the impact of carbon tax on Russia's economy based on the CGE model. The results suggested that the dividend earned by carbon tax is two times that obtained by the labor force. Grant Allan [20] investigated the economic and environmental impact of a Scottish-specific carbon tax under three alternative assumptions: revenues raised are not recycled within Scotland, and revenues are used to increase general government expenditure or to reduce Scottish income tax. It is suggested that a carbon tax might simultaneously stimulate economic activity while reducing emissions and thus secure a double dividend, but only for the case in which the revenue is recycled through income tax. Klimenko, Mikushina, and Tereshin [21] put forward that a carbon tax would lead to the price rise of fuel and electricity, significantly affecting the quality of people's life.

In recent years, research on China's carbon tax has also increased. Wei [22] employed the CGE model to analyze the effects of three carbon tax schemes on the Chinese economy. They found that a carbon tax would cause the deterioration of the Chinese economic situation. Zhe Zhang et al. [23] evaluated the impact of a single policy instrument (carbon tax) and combined policy mixes to investigate driving factors affecting policy performance. The results illustrated that complicated policy mixes are preferred to improve the performance of China's carbon tax. Liu [24] analyzed the impact of carbon tax on China's economy based on the inter provincial panel data of 1999-2007. The results indicated that a carbon tax has a significant effect on energy savings and emissions reduction. In addition, it can effectively adjust the income distribution among elements. However, restricted by China's current economic development level, carbon tax collection will hurt China's economy considerably, so it is not appropriate for short-term levying. Zhang et al. [25] maintained that carbon tax would not have a significant impact on the overall economy. It is argued that the decrease of China's GDP level resulting from carbon tax was only about $0.1 \%$. Wang et al. [26] conducted a simulation investigation of the effects of carbon tax policy on GDP, energy prices, capital prices, and other macroeconomic variables by adopting a recursive dynamic general equilibrium model. Lu et al. [27] investigated the impact of carbon tax on the economy at the tax rate of 50 yuan/t, 100 yuan/t, 200 yuan/t, and 300 yuan/t based on the CGE model.

In addition, several studies have evaluated the effect on specific industrial levels. Naraka et al. [28] discussed the impact of carbon tax on energy-intensive industries in Japan employing the partial equilibrium model. Zhu et al. [29] evaluated the impacts of the high, medium, and renewable tax rates on 121 Chinese sectors' output. Among these sectors, the greatest influence is the coal and coking industry. Qiao-Mei Liang et al. [30] surveyed five major energy-intensive sectors and 
explored the impact of a carbon tax on their output, prices, and emissions, along with suggested exemption and subsidy measures to alleviate the negative impacts on these sectors. Li et al. [31] assessed the impact of carbon tax on 35 industries under China's 2020 emission reduction targets based on the interval gray system prediction theory. The study suggested that about $23 \%$ of the industries were significantly affected, and $32 \%$ of the industries were without sensitivity. This research also proposed taking the quota tax rate and establish a compensation mechanism for the high energy consumption industries.

Meanwhile, in terms of analysis techniques, the most popular models for simulating environment policy effect can be universally referred to the GARCH model [32], input-output models [33], and computable general equilibrium (CGE) model $[34,35]$. Compared with other methods, the CGE model possesses its unique merit in policy simulations by providing a comprehensive analysis under the general equilibrium framework. The CGE model not only describes the overall Chinese economy in each detailed sector, but also systematically analyzes the internal relationship across departments. Therefore, in this paper, a model of fairly standard CGE approach that adds China's environment block covering carbon tax policy is constructed, and then the impact of carbon tax on China's economy and environment is simulated under a tax rate of 0-100 yuan/ $\mathrm{t} \mathrm{CO}_{2}$.

Based on the existing research results, we find that the carbon tax effect was wildly researched; however, only a few of these studies have focused on the effect on an industrial level. What are the benefits or disadvantages of a sector obtained from carbon tax and why? Different research has given different answers. Furthermore, macro-level analysis does not consider the effect on the overall economy. Due to significant differences among sectors, it is crucial to uncover the sectoral disparities of carbon tax effect on both economic development and carbon reduction so that key sectors for carbon tax implementation can be recognized. Therefore, the main objective of this study is to provide comprehensive analysis for the implementation of a carbon tax in China and discuss policy implications for China based on an environment CGE model. Specially, we developed an environment computable general equilibrium (ECGE) model covering carbon tax policy to simulate the impact of carbon tax on China's overall macroeconomic factors (real GDP, household welfare, total investment, etc.), total $\mathrm{CO}_{2}$ emissions, sectoral output, sectoral $\mathrm{CO}_{2}$ emissions, as well as the impacts of different tax rate policies. In addition, we introduce energy efficiency into the study. This article makes a more systematic study of the impact of carbon tax policy on China's economy and environment based on the latest data (SAM2012). Furthermore, our findings may also have general implications during the policy decision process and lay a solid foundation for the carbon tax introduction.

\section{Methods and Data}

An environment computable general equilibrium (ECGE) model is developed in this section to explore the effects of carbon tax on China's economy and environment. There are six blocks of production, market, income, expenditure, environment, macro closure, and equilibrium block described in the ECGE model.

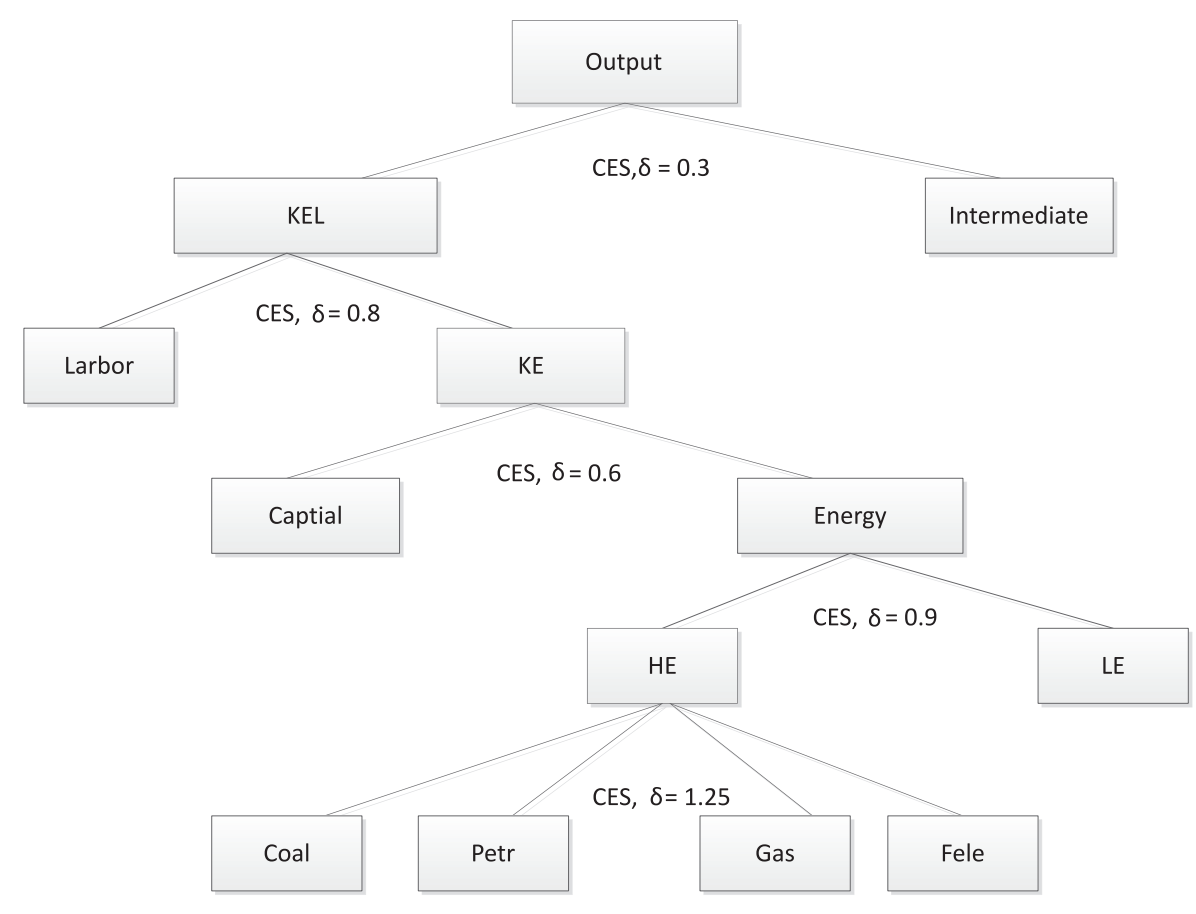

Fig. 1. Framework of production block 


\section{Production Block}

The production block represents the structure of the production functions and is illustrated in Fig. 1.

In this model, each producer (represented by an activity) is assumed to follow the principal of maximizing revenues. The ECGE model covers 11 industries and seven kinds of production inputs (capital, labor, coal, oil, natural gas, low carbon energy, and intermediate input). There are 5 levels of constant elasticity of substitution (CES) function in the production block.

At the first level, the intermediate input and capitalenergy-labor composition constitute sectoral output in a constant elasticity of substitution (CES) function form. The intermediate input does not include energy input, and the intermediate input price is the domestic demand synthetic price for the product.

$$
\begin{gathered}
Q X_{a}=A_{a}\left[\sigma_{a}^{k e l} K E L_{a}^{\rho_{a}}+\left(1-\sigma_{a}^{k e l}\right) N D_{a}^{\rho_{a}}\right]^{1 / \rho_{a}}(1) \\
U N D_{a}^{a a}=i_{a}^{a a} \cdot N D_{a}
\end{gathered}
$$

...where $Q X_{a}$ is the aggregate output of sector a. $K E L_{a}$ represents the composite capital-energy-labor input in sector a, $N D_{a}$ represents the intermediate input of sector a, $U N D_{a}^{a a}$ is the demand of sector aa for per unit output of sector a, $A_{a}$ is the shift parameter in CES function of aggregate output, $\sigma_{a}^{k e l}$ depicts the CES share parameter of capital-energy-labor aggregation in overall output composition, and $\rho_{a}$ is the substitution parameter between the capital-energy-labor input and intermediate input.

The second level assumes that labor (L), capital (K), and energy (E) are aggregated into capital-energy-labor composites using a $(\mathrm{K} / \mathrm{E}) / \mathrm{L}$ structure in a CES function form. The production function at this level is presented in the following equation:

$$
K E L_{a}=A_{a}^{k e l}\left[\sigma_{a}^{k e} K E_{a}^{\rho_{a}^{k e l}}+\left(1-\sigma_{a}^{k e}\right) L_{a}^{\rho_{a}^{k e l}}\right]^{1 / \rho_{a}^{k e l}}
$$

...where $K E_{a}$ is the composite capital-energy input of industry a, $L_{a}$ is the labor input of industry a, $A_{a}{ }^{k e l}$ denotes the shift parameter in capital-energy-labor CES function, $\sigma_{a}^{k e}$ represents the share parameter of capital-energy incorporation in capital-energy-labor aggregation, and $\rho_{a}^{k e l}$ is the substitution parameter between the capital-energy aggregation and labor input.

At the third level, capital and energy are aggregated into capital-energy composition following a CES function. The production function at this level is expressed in the following equation:

$$
K E_{a}=A_{a}^{k e}\left[\sigma_{a}^{k} K_{a}^{\rho_{a}^{k e}}+\left(1-\sigma_{a}^{k}\right) E_{a}^{\rho_{a}^{k e}}\right]^{1 / \rho_{a}^{k e}}
$$

...where $K_{a}$ is the composite capital-energy input of industry a, $E_{a}$ is the energy input of industry a,
$A_{a}^{k e}$ represents the shift parameter in capital-energy CES function, $\sigma_{a}^{k}$ is the share parameter of capital in capital-energy composition, and $\rho_{a}^{k e}$ is the substitution parameter between capital input and energy input.

At the fourth level, energy composition is constitutive of high-carbon energy and low-carbon energy following a CES function, which is presented in the following equation:

$$
E_{a}=A_{a}^{e}\left[\sigma_{a}^{h e} H E_{a}^{\rho_{a}^{e}}+\left(1-\sigma_{a}^{h e}\right) L E_{a}^{\rho_{a}^{e}}\right]^{1 / \rho_{a}^{e}}
$$

...where $H E_{a}$ is the high carbon energy input of industry a, $L E_{a}$ is the low-carbon energy input of industry a, $A_{a}^{e}$ represents the shift parameter in energy CES function, $\sigma_{a}^{\text {he }}$ is the share of high-carbon energy in energy incorporation, and $\rho_{a}^{e}$ is the substitution parameter between high- and low-carbon energy.

At the fifth level, coal, oil, natural gas, and thermal power are aggregated into high-carbon energy composition following a CES function. The production function at this level is shown in the following equation:

$$
\begin{aligned}
H E_{a}= & A_{a}^{h e}\left[\sigma_{a}^{\text {coal }} \text { coal }_{a}^{\rho_{a}^{h e}}+\sigma_{a}^{\text {petr }} \text { petr }_{a}^{\rho_{a}^{h e}}+\sigma_{a}^{\text {gas }} \text { gas }_{a}^{\rho_{a}^{h e}}\right. \\
& \left.+\left(1-\sigma_{a}^{\text {coal }}-\sigma_{a}^{\text {petr }}-\sigma_{a}^{\text {gas }}\right) \text { fele }_{a}^{\rho_{a}^{h e}}\right]^{1 / \rho_{a}^{h e}}
\end{aligned}
$$

...where coal $_{a}$, petr ${ }_{a}$, gas $_{a}$, are the coal, oil, natural gas input of industry a; fele is the thermal power input of industry a; $A_{a}^{\text {he }}$ denotes the shift parameter in high carbon energy CES function; $\sigma_{a}^{\text {coal }}, \sigma_{a}^{\text {petr }}, \sigma_{a}^{\text {gas }}$, are the CES share parameter of coal, oil, and natural gas in high carbon energy composition; and $A \rho_{a}^{h e}$ is the substitution parameter in the energy aggregate function.

\section{Market Block}

In this model, domestic consumption, domestic production, import, and export are converted by the following two methods, as illustrated in Fig. 2. The import decision follows the principle of minimum cost. The Armington [36] assumption is adopted in the ECGE model, and it is assumed that there is

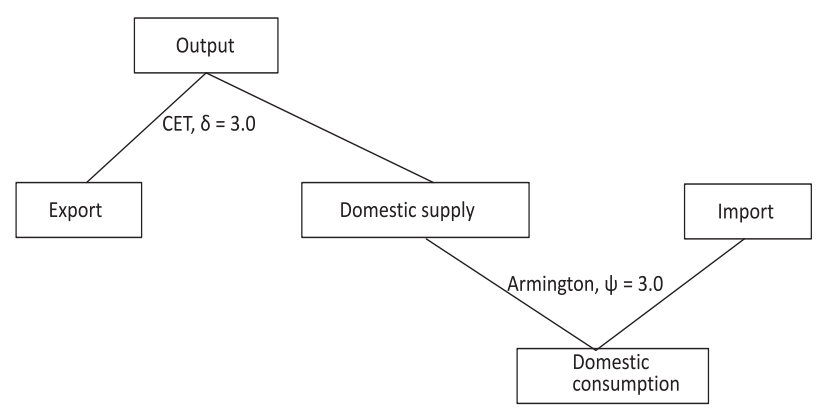

Fig. 2. Framework of market block 
imperfect immutability between imports and domestic production. As for export, this model employs a constant elasticity transformation (CET) function to assign total domestic output between exports and domestic consumption. The function of market block is shown in the following equation:

$$
Q Q_{a}=\gamma_{m a}\left[\delta d_{a}\left(Q D_{a}\right)^{\rho_{m a}}+\left(1-\delta d_{a}\right) \cdot\left(Q M_{a}\right)^{\rho_{m a}}\right]^{1 / \rho_{m a}}
$$

...where $Q D_{a}$ is domestic production of commodity a, $Q M_{a}$ is the imported commodity a, $\gamma_{m a}$ depicts the shift parameter in Armington function, $\delta d_{a}$ is the Armington share parameter of domestic production in domestic consumption composition, and $\rho_{m a}$ represents the substitution parameter in Armington function.

$$
Q X_{a}=\gamma_{e a}\left(\varepsilon d_{a} \cdot Q D_{a}^{\rho_{e a}}+\varepsilon e_{a} \cdot Q E_{a}^{\rho_{e a}}\right)^{1 / \rho_{e a}}(8)
$$

...where $Q D_{a}$ is domestic production of commodity a, $Q E_{a}$ is the exported of commodity a, $\gamma_{e a}$ represents the shift parameter in CET function, $\varepsilon d$ denotes the CET share parameter of domestic production in domestic consumption composition, and $\rho_{m a}$ is the substitution parameter in CET function.

\section{Income and Expenditure Block}

\section{Household Income and Expenditure}

Household income (YH) comes from labor, capital and government transfer payments. Households decide their own consumption according to the principle of utility maximization. The household expenditure covers commodity consumption and income tax. The surplus forms the household savings. It is shown in the following equations:

$$
\begin{gathered}
Y H=w \cdot Q L S+\text { shif }_{h k} \cdot r \cdot Q K S+\text { transfr }_{h g} \\
+ \text { rate }_{h w} \cdot \sum_{a} P M_{a} \cdot Q M_{a}+\text { transfr }_{h e} \\
P Q_{a} \cdot H D_{a}=\text { shrh }_{a} \cdot m p c \cdot(1-t h) \cdot Y H \\
S H=(1-t h) \cdot Y H-\sum_{a} P Q_{a} \cdot Q H_{a}
\end{gathered}
$$

...where $w$ is the price of labor, $r$ is the capital price, $Q L S$ represents the gross labor supply, $Q K S$ denotes the gross capital supply, transfr $r_{h g}$ is transfer payments from the government to the household, transfr $r_{h e}$ is transfer payments from the enterprise to the household, shif $f_{h k}$ is the share of capital elements to household, rate riw $_{h w}$ is the proportion coefficient of residents' foreign income, $\sum P M_{a} \cdot Q M_{a}$ is total value of imported products, $P Q_{a}$ is the composite price of commodity a, $H D_{a}$ is the consumption of commodity a by household, shrh is the consumption share of commodity a in the total consumption of household, th is the personal income tax rate, $m p c$ is the marginal propensity to consume, $\mathrm{YH}$ represents household income, and $\mathrm{SH}$ represents household savings.

\section{Enterprise Income and Expenditure}

The enterprise income is mainly from the return to capital. The enterprise expenditure consists of three parts: the transfer payment of enterprise to residents, the investment demand, and the enterprise savings. It is shown in the following equation:

$$
\begin{gathered}
\text { transfer }_{\text {he }}=\text { rate }_{\text {he }} \cdot Y E N T \\
Y E N T=\text { shif }_{\text {ent }} \cdot r \cdot Q K S+\text { transfr }_{\text {entg }} \\
I N V_{a}=\text { in }_{a} \cdot(S E+S H+S G+\overline{S F}) / P Q_{a} \\
S E=(1-\text { tent }) \cdot Y E N T-\text { transfer }_{\text {he }}
\end{gathered}
$$

...where shif $_{\text {entk }}$ is the share of capital elements to enterprise; transfer ${ }_{\text {entg }}$ is transfer payments from the government to the enterprise; YENT is the total income of enterprise; rate is $_{\text {is }}$ proportion coefficient of enterprise transfer payment to residents; INV $V_{a}$ represents the investment demand of commodity $\mathrm{a} ;{ }^{a}$ in $n_{a}$ is the invest share of commodity a in the total investment; $S H, S E$, and $S G$ are household, enterprise, and government savings; $S F$ is foreign savings; and tent represents the corporate income ax rate.

\section{Government Income and Expenditure}

Government income consists of personal income tax, enterprise income tax, foreign capital income, indirect tax, and tariff. Government expenditure encompasses government transfers to residents, government savings, and government consumption of commodity a.

$$
\begin{gathered}
Y G=\text { th } \cdot Y H+\text { tent } \cdot Y E N T+\sum_{a} G I T A X_{a}+\sum_{a} G T T A X_{a}+G W Y \\
G W Y=\text { rate }_{g w} \cdot \sum_{a} P M_{a} \cdot Q M_{a} \\
\operatorname{transfr}_{h g}=\operatorname{rate}_{h g} \cdot Y G \\
S G=s g \cdot Y G \\
G D_{a}=\mu_{g a} \cdot\left(1-\text { rate }_{h g}-s g\right) \cdot Y G / P Q_{a}
\end{gathered}
$$

...where $Y G$ is government income, $\sum_{a}$ GITAX $_{a}$ denotes indirect tax, $\sum_{a}$ GTTAX $_{a}$ depicts tariff, GWY represents 
transfers from other countries, rate gw $_{\text {represents }}$ proportion coefficient of government income from other countries, $s g$ denotes the saving rate of government, $G D_{a}$ is the consumption of commodity a by government, and $\mu_{g a}$ is the consumption share of commodity a in the total consumption of government.

\section{Environment Block}

The block is the main characteristic distinguishing the general CGE and ECGE models covering the carbon tax policy this study described, and it is also an important breakthrough point to simulate and analyze the impact of carbon tax policy on the economic system. In the environment block, $\mathrm{CO}_{2}$ emissions were calculated and carbon tax design was carried out.

Firstly, according to the method recommended by the IPCC, $\mathrm{CO}_{2}$ emissions could be calculated by multiplying the demands for fossil fuels based on their corresponding potential carbon emission factor and fraction of oxidized carbon. To avoid repeated counting, only emissions from primary energies are calculated here.

In this model, the carbon tax is based on the amount of $\mathrm{CO}_{2}$ emissions, and we employ the international common tax method that levies carbon tax in the use of fossil energy.

The environment block can be explained by the following equations:

$$
\begin{gathered}
C O_{2 a}=\sum_{j} E_{a j} \times \lambda^{j} \quad j=\text { coal, petr, gas } \\
C O_{2 j}=\left(H D_{j}+G D_{j}\right) \cdot \lambda^{j}
\end{gathered}
$$

$$
\operatorname{EITAX}_{j}=t c \cdot \sum_{a} E_{a, j} \cdot \lambda^{j} \quad j=\text { coal, petr, gas }
$$

$$
\text { TCTAX }=\sum_{j} \text { EITAX }_{j} \quad j=\text { coal, petr, gas }
$$

$$
T C O=\sum_{a} \mathrm{CO}_{2 a}+\sum_{j} \mathrm{CO}_{2 j} \quad j=\text { coal, petr, gas }
$$

...where $\mathrm{CO}_{2 a}$ denotes the $\mathrm{CO}_{2}$ emission of industry a, $\mathrm{CO}_{2}$ is the $\mathrm{CO}_{2}$ emission of energy $\mathrm{j}$ in the process of final use, TCO is the total $\mathrm{CO}_{2}$ emission, $\lambda^{j}$ represents carbon dioxide emission factor of the 3 primary energies, EITAX represents carbon tax levied on intermediate inputs of fossil fuels $\mathrm{j}$, and TCTAX is the total carbon tax.

After calculating the carbon tax of fossil fuels, the carbon tax rate can be converted to an ex valorem tax rate. The calculation formula is:

$$
t_{c j}=\frac{\text { EITAX }_{j}}{P Q_{j} \cdot Q Q_{j}}
$$

Therefore, the consumption price of fossil energy will be $\left(1+t_{c j}\right) \cdot P Q_{j}$, which has a direct impact on the input cost of the fifth-level production function. Meanwhile, the government income function will be changed as the following equation:

$$
\begin{gathered}
Y G=\text { th } \cdot Y H+\text { tent } \cdot Y E N T+\sum_{a} \text { GITAX }_{a} \\
+\sum_{a} \text { GTTAX }_{a}+G W Y+\text { TCTAX }
\end{gathered}
$$

\section{Macro Closure Block}

Macro closure is an indispensable part of maintaining the integrity of the CGE model. Its essence is to close the model by increasing the number of exogenous variables or by deleting some equations [37]. In this paper, two principles of closure are considered: foreign trade balance and investment-saving balance.

For the foreign trade balance, exchange rate is assumed to be endogenous and savings in foreign countries is assumed to be exogenous, which is illustrated as follows:

$\sum_{a} P M_{a} \cdot Q M_{a}+Y W K+Y W G=\sum_{a} P E_{a} \cdot Q E_{a}+Y H W+G W Y+\overline{S F}$

As for the invest-saving balance, this model follows the principle of neoclassical closure, and assumes that the gross investment equals the whole savings:

$$
\begin{gathered}
T I N V=\sum_{a} I N V_{a} \cdot P Q_{a} \\
T S A V=S E+S G+S H+\overline{S F} \\
T I N V=T S A V+W A L A R S
\end{gathered}
$$

...where TINV represents gross investment, TSAV represents the whole savings, and WALARS is a virtual variable used to check whether investment equals savings.

\section{Equilibrium Block}

The equilibrium block covers commodity markets equilibrium and factor markets equilibrium.

In terms of the commodity markets equilibrium, it is required that the aggregate supply of a commodity must equal the whole demand for that commodity. The aggregate demand of a commodity covers household consumption, government consumption, investment demand, and the demand for intermediate input, which can be presented as follows: 


$$
H D_{a}+G D_{a}+I N V_{a}+N D_{a}=Q Q_{a}
$$

For the factor market, it is implied that the capital market could realize full adjustment under external shocks and the labor market could guarantee full employment [37]. It is required in the capital market equilibrium that the total capital demand from all the sectors equals the exogenous overall supply of capital. Similarly, in the labor market it is assumed that the total labor demand is equivalent to the overall supply of labor.

$$
\begin{gathered}
\sum_{a} K_{a}=Q K S \\
\sum_{a} L_{a}=Q L S
\end{gathered}
$$

\section{Data and Parameter Calibration}

The database of this study is the social accounting matrix 2012 (SAM 2012), which is illustrated in Table 1. SAM is a data matrix expression of the specific economic relationships between the various ports and the economic entities in the national economic system, and could reflect overall economic activity in detail. The data source of the SAM in this study is from China's national input-output (IO) table 2012 [38], the National Bureau of Statistics of P.R. China [39], and the China Fiscal Yearbook 2013 [40]. Then, according to the needs of this study, the sectors are divided into 11 departments (Table 2).

Based on SAM 2012, a calibration process is conducted to determine the parameters in the model. Exogenous parameters in this model include substitute elasticities in the product block and the market block as
Table 2. Description of sector classification.

\begin{tabular}{|c|c|}
\hline Sectors & Description \\
\hline Agri & $\begin{array}{c}\text { Agriculture, forestry, animal husbandry, } \\
\text { and fishery }\end{array}$ \\
\hline Hindus & Heavy industry \\
\hline Lindus & Light industry \\
\hline Stran & Transportation \\
\hline Buil & Construction industry \\
\hline Serv & The tertiary industry \\
\hline Coal & Coal mining and washing industry \\
\hline Petr & Petroleum exploitation and coking industry \\
\hline Gas & Natural gas production and supply industry \\
\hline Efele & Thermal power production and supply industry \\
\hline Rene & Renewable energy \\
\hline
\end{tabular}

well as carbon emission factors in the environment block. There are two main methods to estimate substitution elasticities. One is the method of econometrics and the other is a reference to related studies. Here, based on the second method, we estimate the substitution elasticity of the CES function in each department according to related studies [41].

There are three main methods to determine carbon dioxide emission coefficients. According to carbon emission factors of fossil energy from IPCC, the conversion of physical energy consumption and actual heat is adopted in the first method. The second method is a direct reference to the carbon emission factor in the Japanese energy economic statistics manual. The third method is to calculate the actual consumption of energy

Table 1. Social accounting matrix in 2012 (billion yuan).

\begin{tabular}{|c|c|c|c|c|c|c|c|c|c|c|c|}
\hline & $\mathrm{A}$ & $\mathrm{C}$ & $\mathrm{L}$ & $\mathrm{CA}$ & $\mathrm{HH}$ & $\mathrm{ENT}$ & GOV & IFA & IC & F & Total \\
\hline $\mathrm{A}$ & & 1464961 & & & & & & & & 136666 & 1601627 \\
\hline $\mathrm{C}$ & 1064827 & & & & 198537 & & 73182 & 255335 & 12692 & & 1604572 \\
\hline $\mathrm{L}$ & 264134 & & & & & & & & & & 264134 \\
\hline CA & 199060 & & & & & & & & & & 199060 \\
\hline HH & & & 264134 & 24336 & & 16343 & 16585 & & & & 321400 \\
\hline ENT & & & & 178348 & & & & & & & 178348 \\
\hline GOV & 73606 & 17586 & & & 5820 & 19655 & & & & -196 & 116472 \\
\hline IFA & & & & & 117042 & 142350 & 26705 & & & -18070 & 268027 \\
\hline IC & & & & & & & & 12692 & & & 12692 \\
\hline F & & 122025 & & -3624 & & & & & & & 118401 \\
\hline Total & 1601627 & 1604572 & 264134 & 199060 & 321400 & 178348 & 116472 & 268027 & 12692 & 118401 & \\
\hline
\end{tabular}

Notes: A is activity, $\mathrm{C}$ is commodity, $\mathrm{L}$ is labor, CA is capital, HH is household, ENT is enterprise, GOV is government, IFA is investment in fixed assets, IC is the inventory change, $\mathrm{F}$ is foreign, Total is the summary. 
Table 3. Macroeconomic impacts of carbon tax at different levels.

\begin{tabular}{|c|c|c|c|c|c|c|c|c|c|c|c|}
\hline $\begin{array}{l}\text { Macroeconomic } \\
\text { Variables }\end{array}$ & TAX0 & TAX10 & TAX20 & TAX30 & TAX40 & TAX50 & TAX60 & TAX70 & TAX80 & TAX90 & TAX100 \\
\hline Real GDP (\%) & 0 & -0.04 & -0.09 & -0.14 & -0.19 & -0.25 & -0.30 & -0.36 & -0.42 & -0.48 & -0.54 \\
\hline Price level (\%) & 0 & 0 & 0.01 & 0.02 & 0.03 & 0.05 & 0.07 & 0.09 & 0.12 & 0.14 & 0.17 \\
\hline Household income (\%) & 0 & 0.03 & 0.06 & 0.09 & 0.11 & 0.14 & 0.16 & 0.18 & 0.20 & 0.21 & 0.23 \\
\hline Government income (\%) & 0 & 0.88 & 1.71 & 2.50 & 3.24 & 3.94 & 4.61 & 5.25 & 5.86 & 6.45 & 7.01 \\
\hline Enterprise income (\%) & 0 & -0.11 & -0.21 & -0.31 & -0.41 & -0.50 & -0.59 & -0.68 & -0.77 & -0.86 & -0.95 \\
\hline Household saving (\%) & 0 & 0.03 & 0.06 & 0.09 & 0.11 & 0.14 & 0.16 & 0.18 & 0.20 & 0.22 & 0.23 \\
\hline Government saving (\%) & 0 & 0.88 & 1.72 & 2.50 & 3.24 & 3.95 & 4.62 & 5.25 & 5.87 & 6.45 & 7.01 \\
\hline Enterprise Saving (\%) & 0 & -0.10 & -0.20 & -0.30 & -0.40 & -0.50 & -0.59 & -0.68 & -0.77 & -0.86 & -0.95 \\
\hline Total investment (\%) & 0 & -0.25 & -0.50 & -0.74 & -0.97 & -1.20 & -1.43 & -1.65 & -1.87 & -2.08 & -2.29 \\
\hline Welfare (\%) & 0 & -0.12 & -0.24 & -0.36 & -0.48 & -0.59 & -0.70 & -0.81 & -0.92 & -1.02 & -1.12 \\
\hline $\begin{array}{l}\text { Household consumption } \\
(\%)\end{array}$ & 0 & -0.11 & -0.22 & -0.32 & -0.43 & -0.53 & -0.63 & -0.72 & -0.82 & -0.91 & -1.00 \\
\hline $\begin{array}{c}\text { Government } \\
\text { consumption }(\%)\end{array}$ & 0 & 0.82 & 1.59 & 2.32 & 3.00 & 3.64 & 4.26 & 4.84 & 5.39 & 5.92 & 6.43 \\
\hline
\end{tabular}

employing the carbon dioxide emissions from fossil energy. Given the country difference of carbon dioxide emission coefficient, in this paper, we mainly refer to the third method.

\section{Results and Discussion}

Tax rate is the core content of a carbon tax policy design. At present, there is not a uniform tax rate in international carbon tax levying. In 2005 the carbon tax rate in Denmark was about $€ 12.1 / \mathrm{t} \mathrm{CO}_{2}$. In 2008 in Finland was close to $€ 20 / \mathrm{t} \mathrm{CO}_{2}$, and in Sweden it was about $\$ 40 / \mathrm{t} \mathrm{CO}_{2}$. From the current research in China, the Ministry of finance of China has proposed a short-term carbon tax rate of 10 yuan/t $\mathrm{CO}_{2}$, and a long-term carbon tax rate of 40 yuan/t $\mathrm{CO}_{2}$. Yao Xin and Liu Xiying [42] found that the optimal carbon tax rate in China was 18.28 yuan/t $\mathrm{CO}_{2}$, which was close to the rate of 20 yuan/t $\mathrm{CO}_{2}$ proposed by the Ministry of Environmental protection of China. Therefore, combined with international experience as well as the economic background of China, we set the tax rate at 0-100 yuan/ton $\mathrm{CO}_{2}$, which is expressed by TAX0TAX100, respectively. Among these, TAX0 is the baseline scenario without a carbon tax.

\section{Macro Effect}

\section{Economic Effect}

The variation of macroeconomic indicators relative to baseline scenario is illustrated in Table 3. GDP is an important indicator to evaluate the social and economic cost of a mitigation policy. As a developing country, in order to meet the increasing material and cultural needs of the people, it is especially important for China to maintain relatively fast economic growth. In this model, the 2012 price serves as a benchmark price, so the GDP we discussed here is real GDP calculated with an expenditure approach, covering the total consumption, investment, and net exports of China. From the results in Table 3, we find that a low tax rate of 10 yuan/t $\mathrm{CO}_{2}$ has a mild negative influence on real GDP only with a loss of $0.04 \%$, and such a negative effect would be increased with a higher tax rate. When the tax rate is set at $10-100$ yuan/t, the real GDP will be reduced by $0.04-0.54 \%$. This result is consistent with previous related studies that the economy will suffer a light loss due to carbon tax policy. For example, Zhou et al. [16] found that the real GDP in China would be cut down by $0.09 \%, 0.20 \%$, and $0.33 \%$, respectively, at carbon taxes of 30,60, and 90 yuan/t $\mathrm{CO}_{2}$. Lu et al. [27] constructed a model to evaluate the carbon tax effects on the Chinese economy, assuming that China introduced a carbon tax in 2013. They found that if the tax rate is 50 yuan/t $\mathrm{CO}_{2}$, the GDP loss would have been $0.19 \%$ in 2013 , which is close to the results of this paper.

Generally speaking, the impact on the macroeconomy is still within a bearable range, so a carbon tax is feasible in China. To reduce the detrimental impact on the economy in the short term, the introduction of a precautionary system can be considered. It is suggested that a tax rate of 10-30 yuan/t $\mathrm{CO}_{2}$ might be appropriate as a starting point in China, and then the tax rate remains stable during an appropriate long period of time. This is confirmed by many researchers. For example, Wang et al. [7] argued that a lower carbon tax rate was a feasible option in China's near future. The low carbon tax rate has a smaller impact on the economy of China, while 
Table 4. Variations of $\mathrm{CO}_{2}$ emissions and $\mathrm{CO}_{2}$ intensity under different carbon tax levels and the contribution of energy-efficiency improvement to $\mathrm{CO}_{2}$ abatement (CEEIA).

\begin{tabular}{|c|c|c|c|c|c|c|c|c|}
\hline \multirow[b]{2}{*}{$\begin{array}{l}\text { Carbon tax } \\
\text { (yuan/ton) }\end{array}$} & \multicolumn{2}{|c|}{ S1 } & \multicolumn{2}{|c|}{ S2 } & \multicolumn{2}{|c|}{ S3 } & \multicolumn{2}{|c|}{ S4 } \\
\hline & $\begin{array}{c}\mathrm{CO}_{2} \\
\text { Emission } \\
(\%)\end{array}$ & $\begin{array}{c}\mathrm{CO}_{2} \text { intensity } \\
(\%)\end{array}$ & $\begin{array}{c}\mathrm{CO}_{2} \\
\text { Emission } \\
(\%)\end{array}$ & $\begin{array}{c}\mathrm{CO}_{2} \text { intensity } \\
(\%)\end{array}$ & $\begin{array}{c}\mathrm{CO}_{2} \\
\text { Emission } \\
(\%)\end{array}$ & $\begin{array}{c}\mathrm{CO}_{2} \text { intensity } \\
(\%)\end{array}$ & $\begin{array}{c}\mathrm{CO}_{2} \\
\text { Emission } \\
(\%)\end{array}$ & $\begin{array}{c}\mathrm{CO}_{2} \text { intensity } \\
(\%)\end{array}$ \\
\hline TAX0 & 0 & 0 & 0 & 0 & 0 & 0 & 0 & 0 \\
\hline TAX10 & -3.06 & -3.02 & -3.21 & -3.21 & -3.36 & -3.40 & -3.66 & -3.79 \\
\hline TAX20 & -5.88 & -5.80 & -6.03 & -5.99 & -6.17 & -6.18 & -6.47 & -6.56 \\
\hline TAX30 & -8.49 & -8.38 & -8.64 & -8.57 & -8.78 & -8.75 & -9.08 & -9.12 \\
\hline TAX40 & -10.93 & -10.78 & -11.07 & -10.97 & -11.21 & -11.15 & -11.50 & -11.51 \\
\hline TAX50 & -13.20 & -13.03 & -13.34 & -13.20 & -13.48 & -13.38 & -13.76 & -13.74 \\
\hline TAX60 & -15.32 & -15.12 & -15.46 & -15.30 & -15.59 & -15.47 & -15.87 & -15.82 \\
\hline TAX70 & -17.31 & -17.09 & -17.45 & -17.26 & -17.58 & -17.43 & -17.85 & -17.77 \\
\hline TAX80 & -19.19 & -18.94 & -19.32 & -19.11 & -19.45 & -19.27 & -19.72 & -19.61 \\
\hline TAX90 & -20.95 & -20.69 & -21.08 & -20.85 & -21.21 & -21.01 & -21.47 & -21.34 \\
\hline TAX100 & -22.62 & -22.33 & -22.75 & -22.49 & -22.87 & -22.65 & -23.13 & -22.98 \\
\hline CEEIA & & & -0.141 & -0.178 & -0.277 & -0.354 & -0.560 & -0.712 \\
\hline
\end{tabular}

it leads to obvious $\mathrm{CO}_{2}$ emissions reduction. Liang [43] held that high carbon tax rate has a substantial adverse effect on the economy and some sectors may be highly adversely affected. Carbon tax should begin with a low tax rate.

Another economic consequence of carbon tax is the effect on economic entities. As presented in Table 3, the carbon tax collection caused an increase in the income of household and government and a decline in the enterprise income. For the government, the carbon tax collection has a direct influence on the income increase. When the tax rate is at 10-100 yuan/t $\mathrm{CO}_{2}$, compared with baseline scenario, the government income will rise significantly - by $0.88-7.01 \%$. Therefore, government consumption will increase by $0.42-6.43 \%$, though the product price has risen. Moreover, government savings will be enhanced. As for households, the increase of household income mainly comes from the rise in nominal factor prices caused by rising general price level. By imposing a rate of $10-100$ yuan/t $\mathrm{CO}_{2}$, the general price level increased by $0-0.17 \%$ and the rise in household income was $0.03-0.23 \%$. In addition, the price rise reduces household consumption ability (0.06-1.0\%), causing a sharp decline $(0.12-1.12 \%)$ in social welfare. In terms of enterprise, the income will be reduced due to a carbon tax policy, and the effect will be increased with a higher tax rate. For example, it declined by $0.11-0.95 \%$ when the tax rate is $10-100$ yuan/t $\mathrm{CO}_{2}$. Moreover, the decrease in income affects the investment ability of enterprises, producing an acceleration number effect. It can be seen from Table 3 that the total investment is reduced by $0.25-2.29 \%$, dropping more than the decline in revenue. In other words, carbon tax will lead to a redistribution of income among economic entities. Increasing the tax rate will further promote the economic effects of carbon tax. Based on the above analysis, we can observe that carbon tax will exert a distortion effect on income distribution and a negative effect on household and enterprise. To mitigate these effects, compensation for residents and enterprises in the manner of government transfer payment is necessary, especially for tax refund of enterprises, which can be applied to energy saving technology improvement, then producing a multiplier effect of emission reduction. Remarkably, the results are also in accordance with those existing related studies such as Liang Q M [30] and Lou [15].

\section{Environmental Effect}

The increase in the cost of fossil energy use caused by carbon tax levying could enable an enterprise to improve energy efficiency through $R \& D$ or other ways. In this way, emission reduction targets will be achieved at a lower cost. According to previous calculations, the energy efficiency improvement rate is about $0.5-2 \%$ in China. Therefore, we set up four scenarios in which energy efficiency increased by $0 \%$ (S1), $0.5 \%$ (S2), $1 \%$ (S3), and $2 \%$. The simulation results are presented in Table 4. In S1, without considering energy efficiency improvement, $\mathrm{CO}_{2}$ emissions are reduced by $3.06-$ $22.62 \%$ and $\mathrm{CO}_{2}$ intensity is reduced by $3.02-22.33 \%$ when imposing a carbon tax rate of $10-100$ yuan/t $\mathrm{CO}_{2}$. It can be observed that carbon tax has a significant reduction effect on $\mathrm{CO}_{2}$ emissions, and the effect increases with a higher tax rate. And the results of $\mathrm{CO}_{2}$ 
emissions reduction meet the research findings of Zhou et al. [16] and $\mathrm{Lu}$ et al. [27]. Zhou [16] found that $\mathrm{CO}_{2}$ emissions would be reduced by $5.56 \%, 10.45 \%$, and $14.74 \%$ at the carbon tax of 30 yuan/t $\mathrm{CO}_{2}, 60$ yuan/t $\mathrm{CO}_{2}$, and 90 yuan/t $\mathrm{CO}_{2}$, respectively. In the study of $\mathrm{Lu}$, for the carbon tax of 50 yuan $/ \mathrm{t} \mathrm{CO}_{2}$, the carbon emissions will be reduced by $3.12 \%$.

To further verify the importance of energy efficiency for emission reduction, we first calculated the discrepancies of carbon emission and intensity in S2, S3, and S4 with S1, then averaged the differences to obtain contribution values at all tax rate levels. The results are shown in Table 4 . The contribution values of $\mathrm{CO}_{2}$ emissions in $\mathrm{S} 2, \mathrm{~S} 3$, and S4 are only $-0.141,-0.277$, and -0.560 , respectively, and the contribution of $\mathrm{CO}_{2}$ intensity is only $-0.178,-0.354$, and -0.712 , respectively. It can be seen that there are no considerable differences in S1, S2, S3, and S4 which is also confirmed by Lou [15]. This illustrates that the energy efficiency improvement would be relatively inefficient for reducing carbon dioxide emissions in comparison with carbon tax in China. In the future, the relatively high cost of reducing carbon emissions in China will require more coercive carbon tax policy, which is almost inevitable.

Furthermore, from the existing studies about $\mathrm{CO}_{2}$ abatement, Chinese carbon intensity was $4.374 \mathrm{t} / \mathrm{ten}$ thousand yuan in 2005 and it dropped to $3.186 \mathrm{t} / \mathrm{ten}$ thousand yuan in 2012. China cut its carbon intensity by $27.04 \%$ until 2012 . With the target of carbon intensity reduced by $40-45 \%$ in 2020 compared to that of 2005 , this is equivalent to a decrease in carbon intensity of around 17.63-24.49\% between 2012 and 2020. The simulation results in Table 4 showed that carbon intensity is reduced by $17.09-22.33 \%$ by imposing a carbon tax rate of 70-100 yuan/t $\mathrm{CO}_{2}$, therefore it can be derived that a tax rate of 70 yuan/t $\mathrm{CO}_{2}$ may be an appropriate rate to realize China's reduction goal in 2020.

\section{Structural Effect}

After the introduction of carbon tax, most sectors generally face the situation of rising costs and decreasing revenues. Moreover, the demand for related products is shrinking, resulting in output decrease across sectors. However, in various departments, due to the differences in the fossil fuels demand and the production function elasticity, the economic and environmental effects of carbon tax will also show structural discrepancies across sectors, as illustrated in the following section.

\section{Economic Effect on Sector Level}

Fig. 3 reports variations of sectoral output under different carbon tax levels. Under the scenarios of TAX10-TAX100, the eight energy or high energyconsuming industries of heavy industry (Hindus), transportation industry (Stran), construction industry (Buil), coal mining and washing industry (Coal), oil mining and processing industry (Petr), natural gas extraction industry (Gas), production and supply of thermal power (Efele), and renewable industry (Rene) suffered larger output losses with an average output decline by $0.95-7.65 \%$, corresponding to the baseline scenario. Coal experiences the largest output reduction by $3.85-28.06 \%$ due to a carbon tax. Then the output decline of Gas ranks second with a ratio of 1.19-10.75\%. The results are inconsistent with most existing related studies. For example, Guo et al. [8] found that the implementation of a carbon tax would negatively affect the energy or high energy-consuming sectors and would have the most adverse influences on Coal. Masoud Yahoo [44] argued that energy sectors are affected substantially due to carbon tax policy in Malaysia. While there are also some sectors of low energy consumption that experience a little output growth with an average increase by $0.09-0.75 \%$ compared with the baseline scenario, including agriculture industry (Agri),

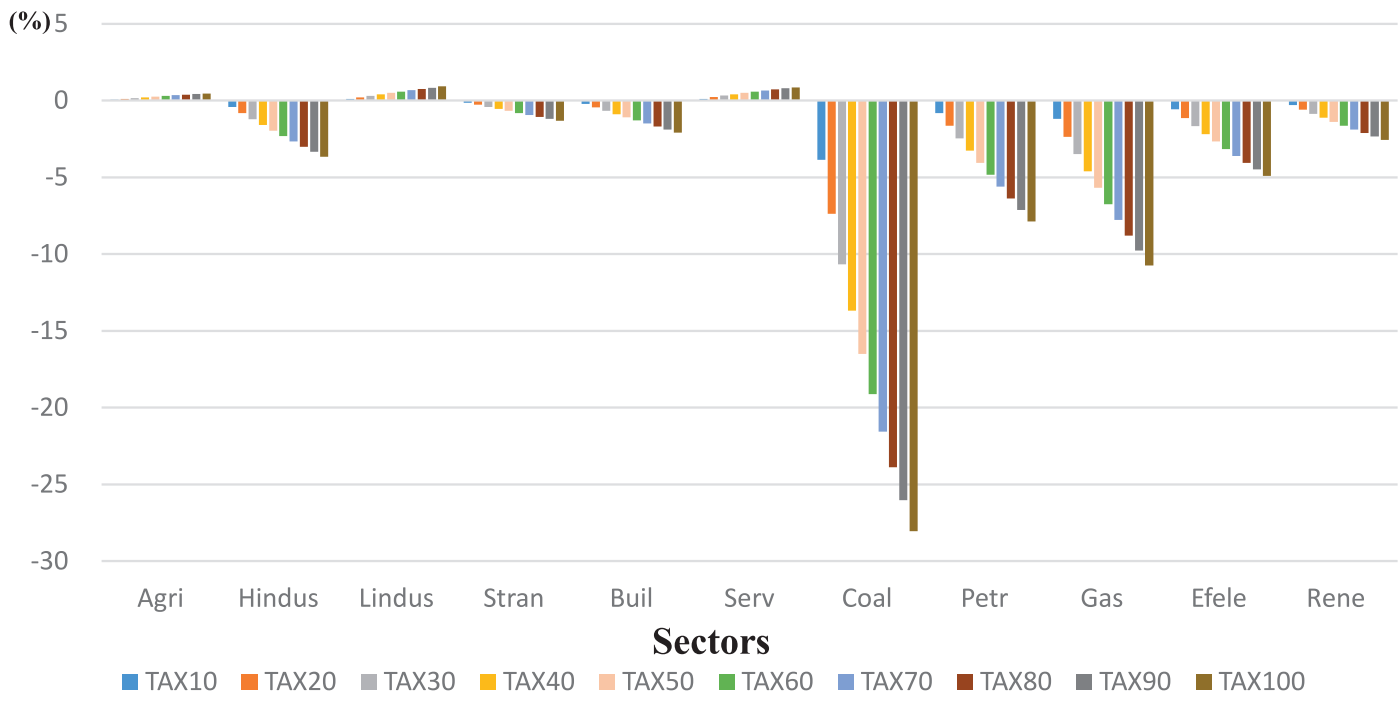

Fig. 3. Variations of sectoral output under different carbon tax levels. 


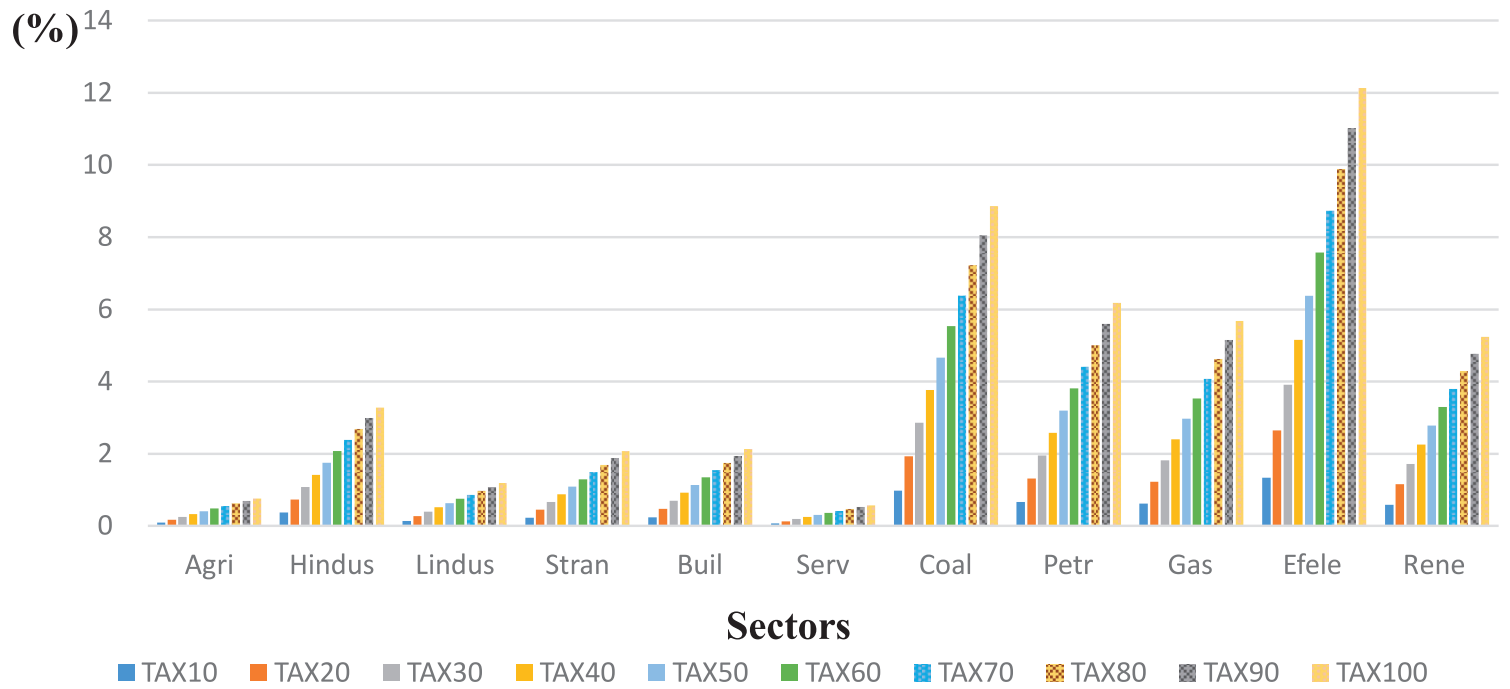

Fig. 4. Variations of sectoral price under different carbon tax levels.

light industry (Lindus), and tertiary industry (Serv). It also corroborates many previous related studies $[8,15$, $40]$ that showed that the implementation of carbon tax in China results in an increase in the output of low-carbon industries.

In a word, the differences on industry level are mainly accounted for following aspects. Firstly, because of the significant difference of $\mathrm{CO}_{2}$ emissions across sectors, carbon tax will exert a remarkable influence on the high-carbon sectors such as Coal, Petr, Gas, and Efele. The additional cost of carbon tax is passed on to consumers through commodity prices, leading to an obvious rise in price. Secondly, the high-carbon sectors are either related to people's livelihood, such as Gas, or to provide energy or raw materials for other industries, such as Coal, Petr, and Efele. Due to the small demand elasticity and slight substitutability of these sectors, levying carbon tax on these industries will indirectly lead to the growth of other industries. Therefore, production cost and output price will rise to some extent, leading to a general price increase. Finally, the distinguished sensitivities of production cost and price to carbon tax vary across different sectors. Specifically, the production cost and price in energy or high energy-consuming industries are more sensitive to carbon tax, leading to a larger rise in production cost and commodity price in these sectors, further encouraging a production and consumption structure transformation to low energy sectors. This conjecture is verified by the impact of carbon tax on sectoral price, as illustrated in Fig. 4. Carbon tax has a remarkable impact on the price of these eight energy

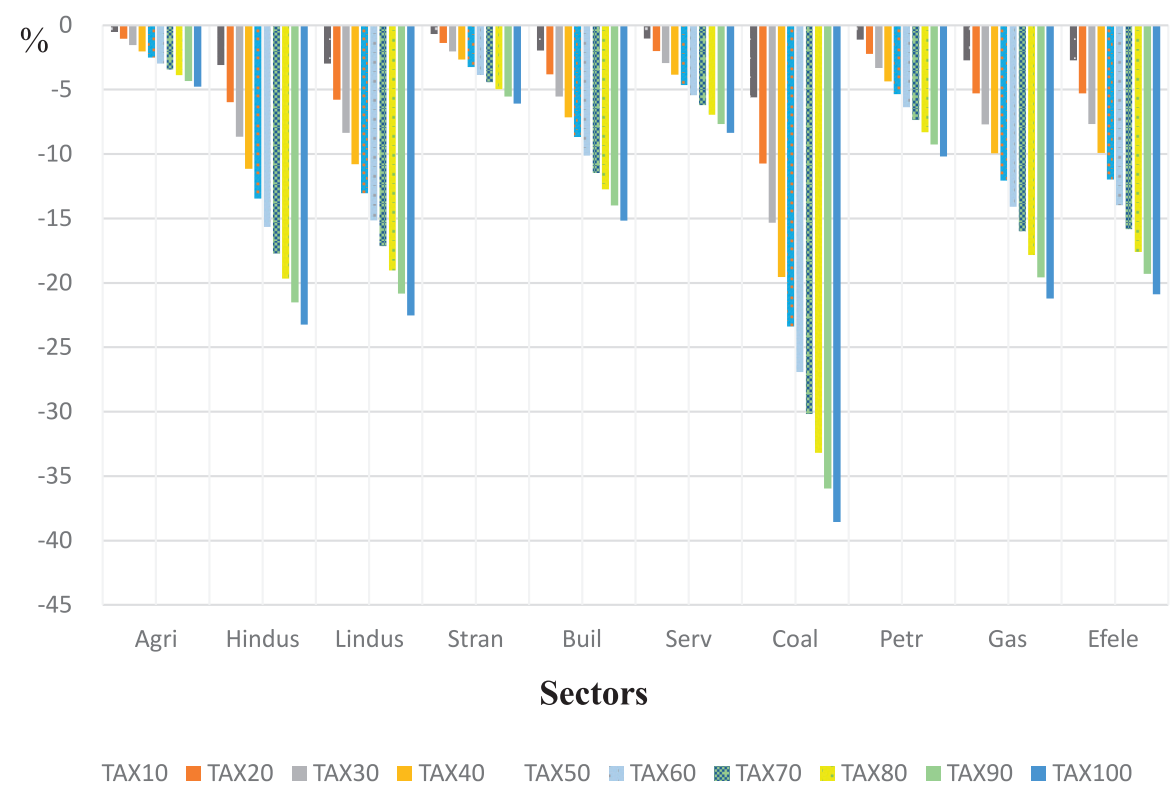

Fig. 5. Variations of $\mathrm{CO}_{2}$ emission under different carbon tax levels. 


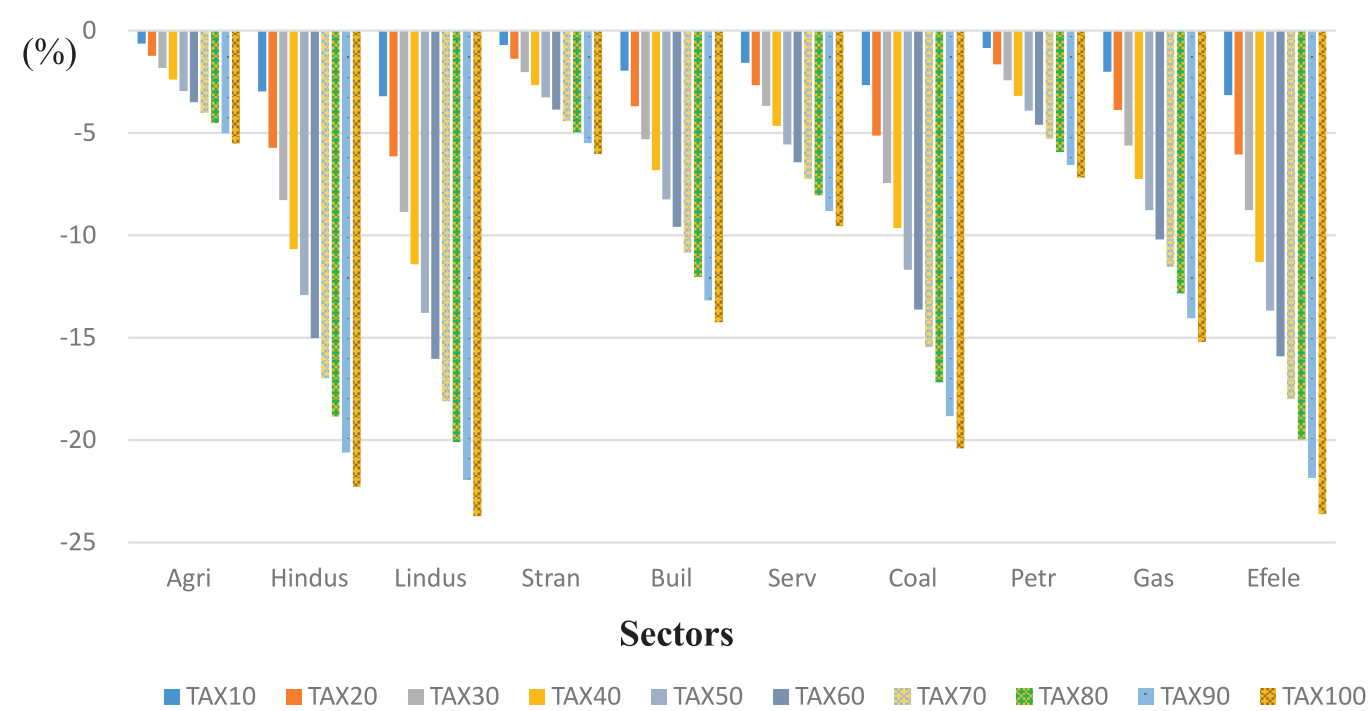

Fig. 6. Variations of $\mathrm{CO}_{2}$ intensity under different carbon tax levels.

or high energy-consuming industries. Compared with baseline scenario, the average price increase in these sectors is $0.63-5.7 \%$, while the shock on the other three low energy-consuming industries is limited, with only an average rise of $0.09-0.84 \%$.

In this study, the impact of carbon tax collection on sectoral profit is evaluated according to the relative change of sectoral output and commodity price. We found that there are four sectors suffering a profit loss, namely Hindus, Coal, Petr, and Gas. Furthermore, profit loss increases with higher tax rates. In the scenarios of TAX10-TAX100, the decline of profit in these four sectors expands from $0.05 \%, 2.87 \%, 0.17 \%$, and $0.57 \%$ to $0.37 \%, 19.19 \%, 1.69 \%$, and $5.06 \%$ with the baseline scenario, respectively. However, the other sectors witness a profit increase either due to the rise of price and output or the amplitude of price rise more than the output decline. Therefore, considering the discrepant impacts of carbon tax on the profit across sectors, a moderate increase in tax return for the most heavily affected sectors (heavy industry and energy industry) is necessary, and it is crucial to implement the differential subsidy policy for reducing policy resistance.

\section{Environmental Effect on Sector Level}

Fig. 5 demonstrates the impacts of different carbon tax rates on sectoral $\mathrm{CO}_{2}$ emissions. From the results it can be obviously concluded that $\mathrm{CO}_{2}$ emissions in the 11 Chinese sectors will be reduced due to carbon tax, and the reduction effect will be increased with a higher tax rate. In comparison with the baseline scenario, when the carbon tax is set at 10-100 yuan/t $\mathrm{CO}_{2}$, the average decrease of $\mathrm{CO}_{2}$ emissions is $2.26-17.09 \%$, of which Coal experienced the largest decrease (by 5.63$38.55 \%$ ), followed by heavy industry, with a reduction of $3.10-23.25 \%$. However, $\mathrm{CO}_{2}$ emissions in sectors like Agri, Lindus, and Serv have mild reductions of 0.53 $4.77 \%, 0.70-6.07 \%$, and $1.04-8.35 \%$, respectively. It is obvious that carbon tax is effective for reducing sectoral carbon emissions, especially for high-carbon sectors such as Coal. Moreover, we found that there is a liner relationship between output effect and $\mathrm{CO}_{2}$ emission reduction effect. The hidden reason lies in the fact that the decline of energy consumption and the increase of production cost play an important role in the carbon tax effects on output and $\mathrm{CO}_{2}$ emissions. Notably, the results are in accordance with most existing related studies [8, 14, 43], which also observed that carbon tax will have a remarkable impact on $\mathrm{CO}_{2}$ emission reduction of energy-intensive sectors.

Furthermore we calculate the carbon intensity change rate to eliminate the decline of carbon emissions caused by sectoral output reduction, as shown in Fig. 6. In the scenarios where the tax rate is set at 10-100 yuan/t $\mathrm{CO}_{2}$, we found that the decreasing rate of carbon intensity in light industry (Lindus) is the largest at $3.10-23.44 \%$, followed by that in Hindus, Efele, and Buil to be 2.68-19.59\%, 2.16-15.97\%, and 1.75-13.07\%, respectively. While the decreasing rate of carbon intensity in Petr is the smallest at $0.30-2.31 \%$, then that in sectors like Agri and Stran is as little as 0.59-5.24\% and $0.57 \%-4.76 \%$. Notably, the results are inconsistent with previous studies $[15,26,40]$.

It is worth mentioning that the above conclusions only reflect the sensitivity discrepancies in emission abatement or intensity reduction to carbon tax across sectors, which does not capture entirely the $\mathrm{CO}_{2}$ abatement potential across sectors. Since the abatement potential depends not only on the relative change rate of carbon emissions due to a carbon tax, but also on the initial emissions of the industry. For example, the change rate of $\mathrm{CO}_{2}$ emissions and intensity in Stran is slight from the baseline level, but the $\mathrm{CO}_{2}$ emissions in transportation industry accounted for $7 \%$ in Chinese $\mathrm{CO}_{2}$ emissions, so the transportation industry should be given a high priority during the abatement potential deciding process. By comparison, as a result of carbon 
tax, the change amplitudes of $\mathrm{CO}_{2}$ emissions and intensity in Lindus is large, while the $\mathrm{CO}_{2}$ emissions share of light industry in Chinese total $\mathrm{CO}_{2}$ emissions is only $2.8 \%$, hence there may actually be a limited $\mathrm{CO}_{2}$ abatement potential in China's light industry.

\section{Conclusions}

To cope with climate change, the introduction of a carbon tax is put on the agenda. In this paper, an ECGE model consisting of an environment block is established to estimate the macro effect and structural effect of carbon tax policy in China. Based on the proposed model, different policy designs at the tax rate of 10-100 yuan/t $\mathrm{CO}_{2}$ are simulated. Generally speaking, the results of the simulation carried out in this paper are consistent with many other studies. It should be noted that the data results vary with the choice of the models as well as some model assumptions. This highlights the importance of model choice and the database.

The main conclusions of this study are as follows:

(1) From the perspective of macroeconomic effects corresponding to the baseline scenario without a carbon tax collection, when the carbon tax rate is set at $10-100$ yuan/t $\mathrm{CO}_{2}$, the GDP loss will be increased by $0.04-0.54 \%$. Generally speaking, the impact on the macro-economy is still within a bearable range. In the short term, the negative impact of China's carbon tax policy on the economy is limited.

Meanwhile, carbon tax will result in the redistribution of social income. Compared to the baseline scenario, as the tax rate is set at 10-100 yuan/t $\mathrm{CO}_{2}$, the household income will increase by $0.03-0.23 \%$ and the government income will rise by $0.88-7.01 \%$. While due to the price rise caused by carbon tax, the household welfare will suffer a loss of $12.43-112.32 \%$. In addition, the enterprise income will decrease by $0.11-0.95 \%$, weakening the investment capability with a decline in the total investment by $0.25-2.29 \%$. Therefore, moderate compensation for residents and enterprises can modify the tax distorting effect of carbon tax to some extent, and help enterprises accelerate the improvement of emission reduction technology.

(2) As for the environment effect on the macro level, carbon tax has a significant effect on emissions reduction. When the carbon tax rate is at $10-100$ yuan/t $\mathrm{CO}_{2}$, Chinese $\mathrm{CO}_{2}$ emissions will be reduced by $3.06-22.62 \%$ corresponding to baseline scenario, and the higher tax rate is the more magnificent the carbon abatement will be. Meanwhile, the simulation result reveals that the contribution of energy efficiency improvement to $\mathrm{CO}_{2}$ abatement is so trifling that it can be negligible. Finally, the simulation result shows that the tax rate of 70 yuan $/ \mathrm{t}$ $\mathrm{CO}_{2}$ may be appropriate for China's carbon intensity target in 2020.
(3) In terms of the economic effect on sectoral level, the average output in the eight energy or high energyconsuming sectors declines by $0.95-7.65 \%$ compared to the baseline scenario, while it rises slightly in the other sectors. The difference between them mainly stems from the larger price increase in the former sectors relative to the latter, then encouraging a conversion of production and consumption to a low-energy consumption structure. At the same time the variations of output and price compared with baseline level induce the profit loss in some sectors like the heavy industry (Hindus), mining and washing of coal (Coal), oil mining and processing industry (Petr), and natural gas extraction industry (Gas). For this reason, it is suggested that transforming tax revenue to the four industries is crucial for reducing their resistance.

(4) From the environmental perspective on the sectoral level, the simulation results demonstrate that relative to baseline scenario, when the carbon tax rate imposed at 10-100 yuan/t $\mathrm{CO}_{2}$ the mining and washing of coal industry (Coal) experiences the largest decrease in $\mathrm{CO}_{2}$ emissions by $5.63-38.55 \%$ and light industry (Lindus) experiences the largest decline in $\mathrm{CO}_{2}$ intensity by $3.10-23.44 \%$. However, it is somewhat arbitrary to confirm the abatement potential in these two industries, because the conclusion should be further analyzed combining the initial emissions.

There are wealthy studies demonstrating the economic and environment effects of carbon tax at a country level, while there are few studies illustrating the carbon tax effects on the sectoral level. In this paper, we simulated the macro and structural effect of carbon tax in China employing an environment CGE model and obtained some interesting conclusions. Meanwhile, we would offer several perspectives for future work in this paper. First, the model established in this paper is static, so there may be some limitations in the analysis of real economic problems. Therefore, it is necessary to enrich the research on dynamic models. Second, the low-carbon energy is not separated to solar, wind, etc., in this study due to the lack of data in China and the share of low-carbon energy is too small. Hence further research would try to separate the low-carbon sectors in detail. Finally, the implementation of carbon tax is a complex process, the object of taxation and the methods of taxation need to be discussed in detail in the future.

\section{Acknowledgements}

The authors gratefully acknowledge financial support from the National Social Science Fund of China (grant No. 17BGL252) and Humanities and Social Sciences of Ministry of Education Planning Fund of China (16YJA790052). 


\section{Conflict of Interest}

The authors declare no conflict of interest

\section{References}

1. ZHANG X.L., VAlERIE J. K., QI T.Y., ZHANG D., HE J.K. Carbon emissions in China: How far can new efforts bend the curve? Energy Econ, 54 (8), 388, 2016.

2. WU H.Q., SHI Y., XIA Q., ZHU W.D. Effectiveness of the policy of circular economy in China: A DEA-based analysis for the period of 11th five-year-plan. Resources Conservation \& Recycling, 83 (1), 163, 2014.

3. PEARCE D. The Role of Carbon Taxes in Adjusting to Global Warming. Econ J, 101 (407), 938, 1991.

4. LIU Y., LU Y. The Economic impact of different carbon tax revenue recycling schemes in China: A model-based scenario analysis. Appl Energy, 141 (1), 96, 2015.

5. BRISTOW A.L., WARDMAN M., ZANNI A.M. Public acceptability of personal carbon trading and carbon tax . Ecological Econ, 69 (9), 1824, 2010.

6. BRETSCHGER L. Carbon policy in a high-growth economy: The case of China. Resource \& Energy Economics, 47, 1, 2016.

7. WANG J.N., YAN G. Studies on Chinese carbon tax in response to climate change. Chin Environ Sci, 29, 101, 2009.

8. GUO Z.Q., ZHANG X.P., ZHENG Y.H., RAO R. Exploring the impacts of a carbon tax on the Chinese economy using a CGE model with a detailed disaggregation of energy sectors. Energy Econ, 45, 455, 2014.

9. FLOROS N., VLACHOU A. Energy demand and energyrelated $\mathrm{CO}_{2}$ emissions in Greek manufacturing: Assessing the impact of a carbon tax. Energy Econ, 27 (3), 387, 2005.

10. WISSEMA W., DELLINK R. AGE analysis of the impact of a carbon energy tax on the Irish economy. Ecol Econ, 61 (4), 671, 2007.

11. BRUVOLL A., LARSEN B.M. Greenhouse gas emissions in Norway: do carbon taxes work? Energy Policy, 32 (4), 493, 2004.

12. GALINATO G.L., YODER J.K. Revenue-Neutral TaxSubsidy Policy for Carbon Emission Reduction. Working Papers, 33 (2008-22), 497, 2009.

13. BARKER T., BAYLIS S., MADSEN P. A UK carbon/ energy tax: The macroeconomics effects. Energy Policy, 21 (3), 296, 1993.

14. MENG S., SIRIWARDANA M., MCNEILL J. The environmental and economic impact of the carbon tax in Australia. Environ. Resour. Econ, 54, 313, 2013.

15. LOU F. Simulation Study on the Carbon Tax Impact on China's Macro Economy and Carbon Emission Reduction. Journal of Quantitative \& Technical Economics, 2014.

16. ZHOU S.L., SHI M.J, LI N.,YUAN Y.N. The effect of carbon tax policy on emission reduction and economic impact. Advances in Climate Change Research, 7 (03), 210, 2011.

17. FANG G., TIAN L., FU M., SUN M. The impacts of carbon tax on energy intensity and economic growth A dynamic evolution analysis on the case of China. Appl Energy, 110 (5), 17, 2013

18. CRISTIAN M., NICOLAS B. Economic and environmental effects of a $\mathrm{CO}_{2}$ tax in Latin American countries. Energy policy, 114, 262, 2018.
19. ANTON O., HARALD G. Carbon Taxation and Market Structure:A CGE Analysis for Russia. Energy Policy, 51, 696, 2012.

20. ALLAN G., LECCA P., MCGREGOR P., SWALES K. The economic and environmental impact of a carbon tax for Scotland: A computable general equilibrium analysis. Ecol Econ, 100 (100), 40, 2014.

21. KLIMENKO V.V., MIKUSHINA O.V., TERESHIN A.G. Do we really need a carbon tax?. Appl Energy, 64, 311, 2011.

22. WEI T.Y., GLOMSROD S. Effects and policy responses of carbon tax. World Economics and Politics 8, 47, 2002.

23. ZHANG Z., ZHANG A.Z., WANG D.P., SONG H.X. How to improve the performance of carbon tax in China? J. Clean. Prod, 142, 2060, 2016.

24. LIU J., LI W. Effects of Introduction Carbon Tax on China's Economy. China Population Resources \& Environment, 21 (9), 99, 2011.

25. ZHANG M.X. CGE Simulation for Levying Carbon Tax in China and International Experience of Levying Carbon Tax. Chinese Journal of Population Resources and Environment, 9 (2), 84, 2011.

26. WANG C., CHEN J.N, JI Z. Impact assessment of $\mathrm{CO}_{2}$ mitigation on China economy based on a CGE model. J Tsinghua Univ. 45 (12), 1621, 2005.

27. LU C., TONG Q, LIU X.M. The impacts of carbon tax and complementary policies on Chinese economy. Energy Policy, 38 (11), 7278, 2010.

28. NAKATA T., LAMONT A. Analysis of the impacts of carbon taxes on energy systems in Japan. Energy Policy, 29 (2), 159, 2001

29. ZHU Y.B., LIU X, WANG Z. Abatement Effect of Carbon Tax and Its Impacts on Economy in China. China Soft Sci, 20 (4), 1, 2010

30. LIANG Q.M., WEI Y.M. Distributional impacts of taxing carbon in China: Results from the CEEPA model. Appl Energy, 92 (2), 545, 2012.

31. LI Y., LAN L., LU M. The influence of carbon tax on energy saving and emission reduction of industrial enterprises. Statistics \& Decision, 16, 174, 2017.

32. SARIANNIDIS N., ZAFEIRIOU E., GIANARAKIS G. ARABATZIS G. $\mathrm{CO}_{2}$ emissions and financial performance of SR firms; The empirical survey of DJSI with a non linear model. Business Strategy and the Environment, 22 (2), 109, 2013.

33. D B.M., WEI W.X., MA X.L., L P. On the impacts of carbon tax and technological progress on China. Appl Econ, 50, 2018

34. WANG K., WANG C., CHEN J.N. Analysis of the economic impact of different Chinese climate policy options based on a CGE model incorporating endogenous technological change. Energy Policy, 37 (8), 2930, 2009.

35. TANG L., SHI J.R, YU L., BAO Q. Economic and environmental influences of coal resource tax in China: A dynamic computable general equilibrium approach. Resour Conserv Recycl., 117, 34, 2017.

36. ARMINGTON P. A theory of demand for products distinguished by place of production.IMF Staff. Pap. 16, 157, 1969.

37. XIAO B.W., NIU D.X., WU H. Exploring the impact of determining factors behind $\mathrm{CO}_{2}$ emissions in China: A CGE appraisal. Science of the Total Environment, 581, 559, 2017.

38. China input-output table. 2012. Available online: http:// www.cioa.org.cn/ 
39. China Statistical Yearbook. 2014. Available online: http:// www.stats.gov.cn/tisj/ndsj/

40. China Fiscal Yearbook. 2013. Available online: http:// www.stats.gov.cn/tjsj/ndsj/

41. LI W., JIA Z.J. The impact of emission trading scheme and the ratio of free quota: A dynamic recursive CGE model in China. Appl Energy, 174, 1, 2016.

42. XIU Y., LIU X.Y. Optimal Carbon Tax in China with the Perspective of Economic Growth. Econ Res J, 2010.
43. LIANG Q.M., FAN Y., WEI Y.M. Carbon taxation policy in China: How to protect energy- and trade-intensive sectors?. J Policy Model, 29 (2), 311, 2007.

44. YAHOO M., OTHMAN J. Employing a CGE model in analyzing the environmental and economy-wide impacts of $\mathrm{CO}_{2}$ emission abatement policies in Malaysia. Sci of the Total Environ, s584-585, 234, 2017. 
